\title{
Breastfeeding is associated with increased lung function at 18 years of age: a cohort study
}

\author{
N. Soto-Ramírez*, M. Alexander*, W. Karmaus*, M. Yousefi*, H. Zhang*, \\ R.J. Kurukulaaratchy ${ }^{\#, \oplus}$, A. Raza ${ }^{\#, \oplus}$, F. Mitchell ${ }^{\#, \oplus}$, S. Ewart ${ }^{+}$and S.H. Arshad ${ }^{\#, 9}$
}

ABSTRACT: Breastfeeding has been linked with increased forced vital capacity (FVC) in children but not in older adolescents. Our aim was to investigate the effects of breastfeeding duration and infant weight gain on FVC in both developmental periods.

In a birth cohort, information on breastfeeding duration was collected at 1 and 2 yrs; spirometric tests were conducted at 10 and 18 yrs. To estimate the effect of breastfeeding duration on FVC at 18 yrs of age, we used linear models; to analyse repeated FVC measurements at 10 and 18 yrs of age, we used linear mixed models. Links between breastfeeding, infant weight gain and FVC at 10 and 18 yrs of age were analysed through path analyses.

Among 808 breastfed children, $49 \%$ were breastfed for $\geqslant 4$ months. At 18 yrs of age the augmenting effect of breastfeeding on FVC was reduced with increased height. Linear mixed models identified that breastfeeding duration was associated with increased FVC. Path analysis suggested a direct effect of breastfeeding on FVC at 10 yrs of age, but an indirect effect at 18 yrs of age via FVC at 10 yrs of age. Although inversely related to breastfeeding, a higher weight gain in infants led to taller adolescents and, in turn, resulted in increased FVC.

In conclusion, a longer duration of breastfeeding contributes to lung health in childhood and adolescence.

KEYWORDS: Adolescence, cohort, lung function

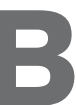

reastfeeding has a number of benefits for both the infant and mother [1-4]. There is strong evidence for a protective effect of breastfeeding against lower respiratory tract infections. However, the effect of breastfeeding on asthma remains controversial. While several studies have reported that exclusive breastfeeding is associated with reduced occurrence of asthma in childhood [2-7], some have found an increased risk with breastfeeding [8, 9], and others have found no association [10-12].

GUILBERT et al. [13] reported that a longer duration of breastfeeding favourably increased forced vital capacity (FVC) at 11 and 16 yrs of age. However, in the presence of maternal asthma, a longer duration of breastfeeding was associated with a decreased FVC [13]. Another cohort study demonstrated that children who were breastfed for $\geqslant 4$ months had significantly higher peak expiratory flow [5]. We previously demonstrated that breastfeeding for $\geqslant 4$ months increases FVC in 10-yr-old children, independent of maternal asthma or allergy [14].

In addition to breastfeeding influencing lung function, TURNER et al. [15] reported that an increase in weight gain during infancy resulted in reduced lung growth. A second study reinforced an inverse association between weight gain and lung volume in infants, but also reported that infant feeding modes were not related to lung function measurements [16]. However, the question arises as to whether increased weight gain during the first year of life is in the "causal pathway" between lack of breastfeeding and lung function and, thus, a substitute marker for lack of or shorter breastfeeding. In addition, neither of these studies analysed whether breastfeeding duration and infancy weight gain were associated with lung function later in childhood and in adolescence $[15,16]$. To date, no study has investigated whether breastfeeding continues to have an effect on lung function in late adolescence.
AFFILIATIONS

*Dept of Epidemiology and Biostatistics, University of South Carolina, Columbia, SC,

${ }^{+}$College of Veterinary Medicine, Michigan State University, East Lansing, MI, USA.

${ }^{\#}$ David Hide Asthma and Allergy Research Centre, Isle of Wight, and 'Dept of Allergy and Clinical Immunology, University of Southampton, Southampton, UK.

CORRESPONDENCE

W. Karmaus

Dept of Epidemiology and Biostatistics, Norman J Arnold School of Public Health University of South Carolina 800 Sumter St Suite 205 Columbia SC 29208 USA E-mail: karmaus@sc.edu

Received: Feb 272011 Accepted after revision: Aug 012011 First published online: Aug 182011 
We hypothesised that both infancy weight gain and breastfeeding duration affect lung capacity in childhood and late adolescence, either directly or indirectly via weight and height. To decipher these composite relationships, a web of associations must be addressed taking the respective time order into account. Thus, we tested our hypothesis by a follow-up study using path analysis. This approach assesses multiple linear equations simultaneously under mutual statistical control and identifies direct and indirect effects. Direct effects indicate the impact of a risk factor on an outcome that is not moderated by other variables, whereas indirect associations depict the effect of a risk factor $(X)$ on an outcome variable $(Z)$ via an intervening variable $(X \rightarrow$ intervening variable $\rightarrow Z)$. The total effect of a risk factor is the combination of direct and indirect statistical links.

\section{MATERIALS AND METHODS Study population}

From January 1989 to February 1990 in the Isle of Wight, UK, 1,536 mother/child pairs were approached at birth to participate in a longitudinal study; $94.8 \%(1,456$ out of 1,536$)$ of mothers were enrolled. The local research ethics committee approved the study and informed written parental consent was obtained for all participants at recruitment and subsequent follow-up conducted at 1, 2, 4, 10 and 18 yrs of age. The Isle of Wight birth cohort has been described in detail elsewhere $[17,18]$. At 10 and 18 yrs of age, lung function tests were performed on all consenting children.

\section{Study design}

We conducted a longitudinal study from birth through to late adolescence using the Isle of Wight birth cohort data. In order to test our hypothesis we investigated: 1) whether the protective breastfeeding effect on lung function was maintained up to 18 yrs of age; and 2) whether first-year weight gain was an intervening variable in the "causal pathway" between breastfeeding duration and lung function at 10 and 18 yrs of age.

\section{Methods}

Information on socio-demographic variables and birth weight were obtained from birth records and enrolment questionnaires. Maternal history of atopic diseases (asthma, eczema or hay fever) and smoking during pregnancy were ascertained at birth. Breastfeeding duration was assessed at follow-up visits at 1 and 2 yrs of age. At 1, 2, 4, 10 and 18 yrs of age, the original questionnaire-based information was updated, and the weight and height of the child were measured. Weight gain during infancy was computed as the difference between birth weight and weight at 1 yr of age.

Lung function measurements were performed at 10 and 18 yrs of age $[14,19]$, including FVC, forced expiratory volume in $1 \mathrm{~s}$ (FEV1) and FEV1/FVC ratio. Lung function measurements were performed using a Koko Spirometer and software with a portable desktop device (both PDS Instrumentation, Louisville, KY, USA), according to American Thoracic Society guidelines [20]. Prior to lung function measurements, children were required to be free from respiratory infection for 14 days and not to be taking oral steroids. In addition, they were required to abstain from any $\beta$-agonist medication for $6 \mathrm{~h}$ and from caffeine intake for at least $4 \mathrm{~h}$.
Breastfeeding was used as a continuous variable in the linear mixed models and path analysis. It was categorised into four groups of breastfeeding duration for linear regression analysis: no breastfeeding; $<2$ months; $2-3$ months; and $\geqslant 4$ months.

\section{Confounders}

Information on maternal smoking during pregnancy (yes/no) and socioeconomic status were obtained. The socioeconomic status was represented by clusters composed of the following information: 1) the British socioeconomic classes (1-6) [21], derived from parental occupation reported at birth; 2) the number of children in the index child's bedroom (collected at 4 yrs of age); and 3) family income at $10 \mathrm{yrs}$ of age. This composite variable captures the family social class across the study period [14]. Family social status cluster was categorised as lower, middle and upper class.

In all explanatory models we adjusted for sex, birth weight $(\mathrm{kg})$ and height $(\mathrm{cm})$ at 10 and 18 yrs of age, as well as maternal body mass index (BMI) before pregnancy (underweight $<18.5 \mathrm{~kg} \cdot \mathrm{m}^{-2}$, normal $18.5-<25 \mathrm{~kg} \cdot \mathrm{m}^{-2}$ and overweight $\geqslant 25 \mathrm{~kg} \cdot \mathrm{m}^{-2}$, following the World Health Organization cut-off points). At 10 and 18 yrs of age, the child's BMI, maternal history of atopic disease (ever eczema, hay fever and asthma) and weight $(\mathrm{kg})$ were used in the repeated measurement models. Weight gain at $1 \mathrm{yr}$ of age, the child's weight and height at 10 and 18 yrs of age, sex and maternal smoking during pregnancy were included in the path analysis.

\section{Analysis}

All statistical analyses were performed using the SAS statistical package (version 9.2; SAS Institute, Cary, NC, USA). To assess whether our analytic sample (children with pulmonary function tests (PFTs)) was representative of the total cohort available at 10 or 18 yrs of age, we compared the characteristics of these two subsets by using the Chi-squared test. Potential effect modification of the breastfeeding effect by height at 18 yrs of age was assessed utilising linear regression modelling. Linear mixed models were employed to determine the association of breastfeeding duration on repeated lung volume measurements at 10 and 18 yrs of age. Adjusted for withinparticipant effects using the regular maximum likelihood method, we started with an unstructured covariance matrix, which requires the least amount of constraints. Other covariance matrices, including compound symmetry and autoregressive, were considered but they did not significantly improve the fit based on the evaluation of the Akaike information criteria and the Bayesian Schwarz information criterion [22]. All covariates were entered as indicator variables into the general linear model and linear mixed model simultaneously. A manual backward elimination process was used to retain confounders for the final model. Confounders were kept in the model if they changed the effect of breastfeeding by $\geqslant 10 \%$.

The possibility that infant weight gain in the first year is in the "causal pathway" between breastfeeding and FVC cannot be tested with either linear regression or repeated measurement models since these models do not address intervening variables. Controlling for an intervening variable as a confounder would split the initial association between the risk factor and the outcome into two associations, destroying the 
"causal pathway". Thus, we explored the relationship between breastfeeding duration, infant weight gain in the first year and FVC at 10 and 18 yrs of age by path analysis [23] using the Covariance Analysis of Linear Structural Equations procedure [24]. Path analysis allowed us to assess the structure among multiple variables and to break down effects into direct, indirect and total (see online supplement). Maximum likelihood parameter estimates were determined by using the nonweighted least-squares estimates of the model parameters and their residuals. The best model had normalised residuals $<2$ and the Chi-squared test was nonsignificant, indicating a good fit. Both the normed and non-normed fit indices exceeded 0.9 [24]. To illustrate the model, we presented the direct effect (path coefficients) only if the effect gained statistical importance (fig. 1). The path coefficients represent the partial correlation between the dependent and independent variables adjusted for other covariates. The direct and indirect pathways of breastfeeding and infant weight gain in the first year on FVC at 10 yrs of age are presented in figure E1 in the online supplement. For the total effect, see figure E2 in the online supplement.

\section{RESULTS}

There were no substantial differences between the total cohort and the sample that had information on lung function, breastfeeding and the covariates of interest (table 1). $77 \%(1,121$ out of 1,456) of children participated in the PFT either at 10 or 18 yrs of age. Among those who participated in the PFT at either age, $91.6 \%(1,027$ out of 1,121$)$ had information on breastfeeding and $219(21.3 \%)$ participants were not breastfed. Among the 808 who were breastfed, $49 \%$ were breastfed for $\geqslant 4$ months.
In the linear regression model for lung function at 18 yrs of age there was an interaction between breastfeeding and height at 18 yrs of age. Thus, the effect of breastfeeding on FVC at 18 yrs of age was modified by height at 18 yrs of age ( $p$-value for breastfeeding $<2$ months $0.25 ; 2-3$ months 0.32 ; and $\geqslant 4$ months 0.04 ; data not shown). Since breastfeeding duration was involved in an interaction with height, we cannot assess the breastfeeding effect on lung volume alone. To disentangle this association, we assessed the effect of each category of breastfeeding on FVC at 18 yrs of age by the children's height. For children with a height of $160 \mathrm{~cm}$, being breastfed for $\geqslant 4$ months was related to an FVC of $4.85 \mathrm{~L}$ compared to $4.62 \mathrm{~L}$ for nonbreastfed children $(p=0.04)$ (table 2$)$. For taller children $(190 \mathrm{~cm})$, the effect of breastfeeding on FVC at $18 \mathrm{yrs}$ of age was diminished or even reversed. However, when ignoring the interaction with height and using a continuous breastfeeding duration variable, the average increase of FVC per week of breastfeeding was $1.6 \mathrm{~mL}$ (data not shown).

Results from linear mixed models indicated that breastfeeding duration was significantly associated with increased FVC, with a $1.48 \mathrm{~mL}$ increase per week of feeding (SE $0.60 \mathrm{~mL} ; \mathrm{p}=0.01$ ) adjusted for sex, age, birth weight, height and BMI, as well as maternal BMI and maternal history of atopic diseases (table 3). Socioeconomic status did not confound the association between breastfeeding duration and FVC. In addition, longer duration of breastfeeding was associated with an increased FEV1 (estimate \pm SE $1.21 \pm 0.58 \mathrm{~mL} ; \mathrm{p}=0.03$ ). Given that both FVC and FEV1 increased with breastfeeding, duration of breastfeeding had no measurable influence on the FEV1/FVC ratio. We will now focus on FVC as the increase in FEV1 was proportional to FVC.

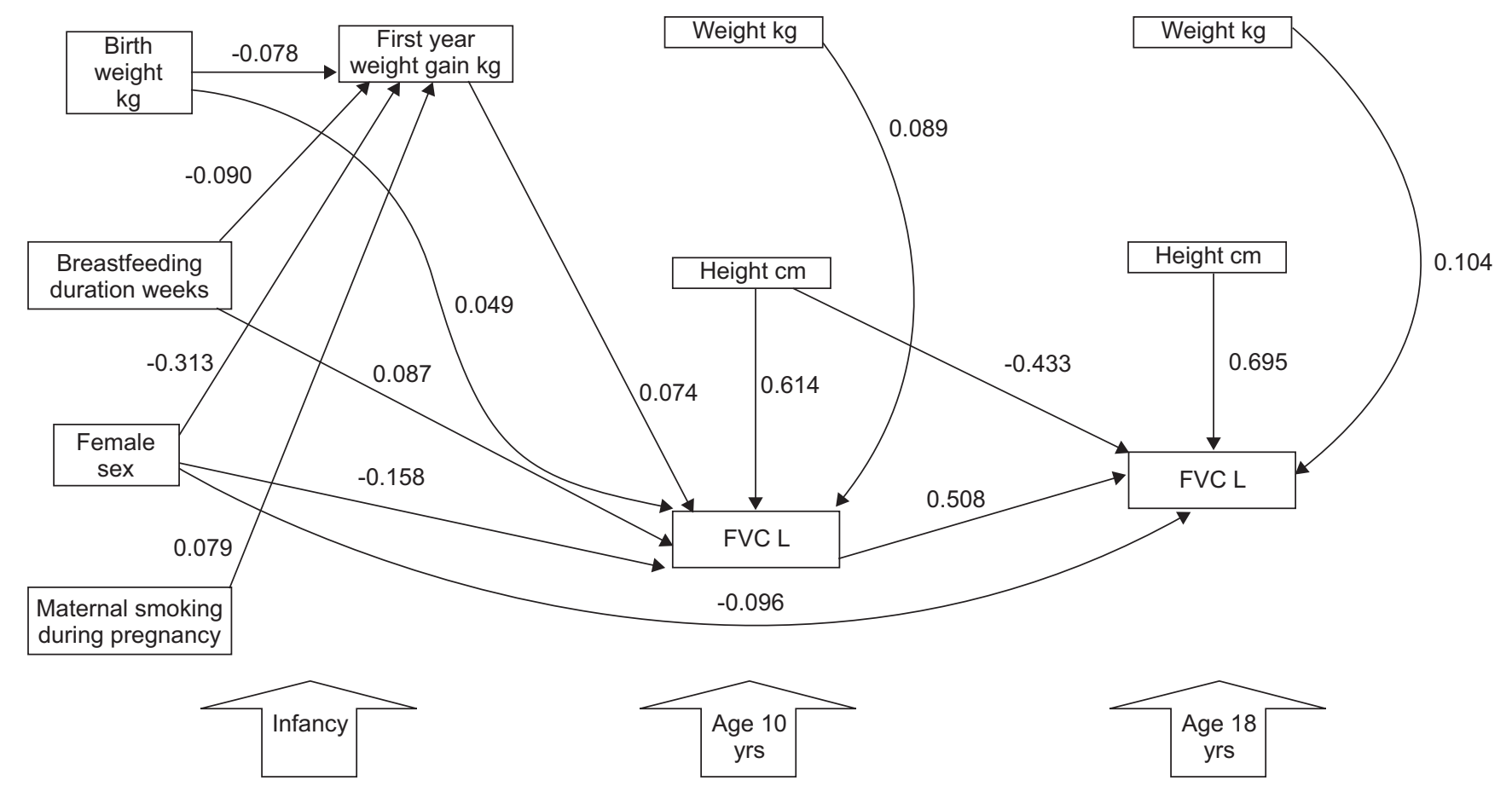

FIGURE 1. Analytical path model exploring the direct effects of birth weight, breastfeeding duration, sex and maternal smoking status during pregnancy on infant weight gain in the first year and forced vital capacity (FVC) at 10 and 18 yrs of age. The path coefficient (direct effects) represents the relative importance between -1 and +1 . Goodness of fit adjusted for degrees of freedom: 0.99; root mean residuals: 0.001; deviation between covariance structure and the empirical covariance: Chi-squared/degree of freedom $\leqslant 2 ; p<0.05$. 


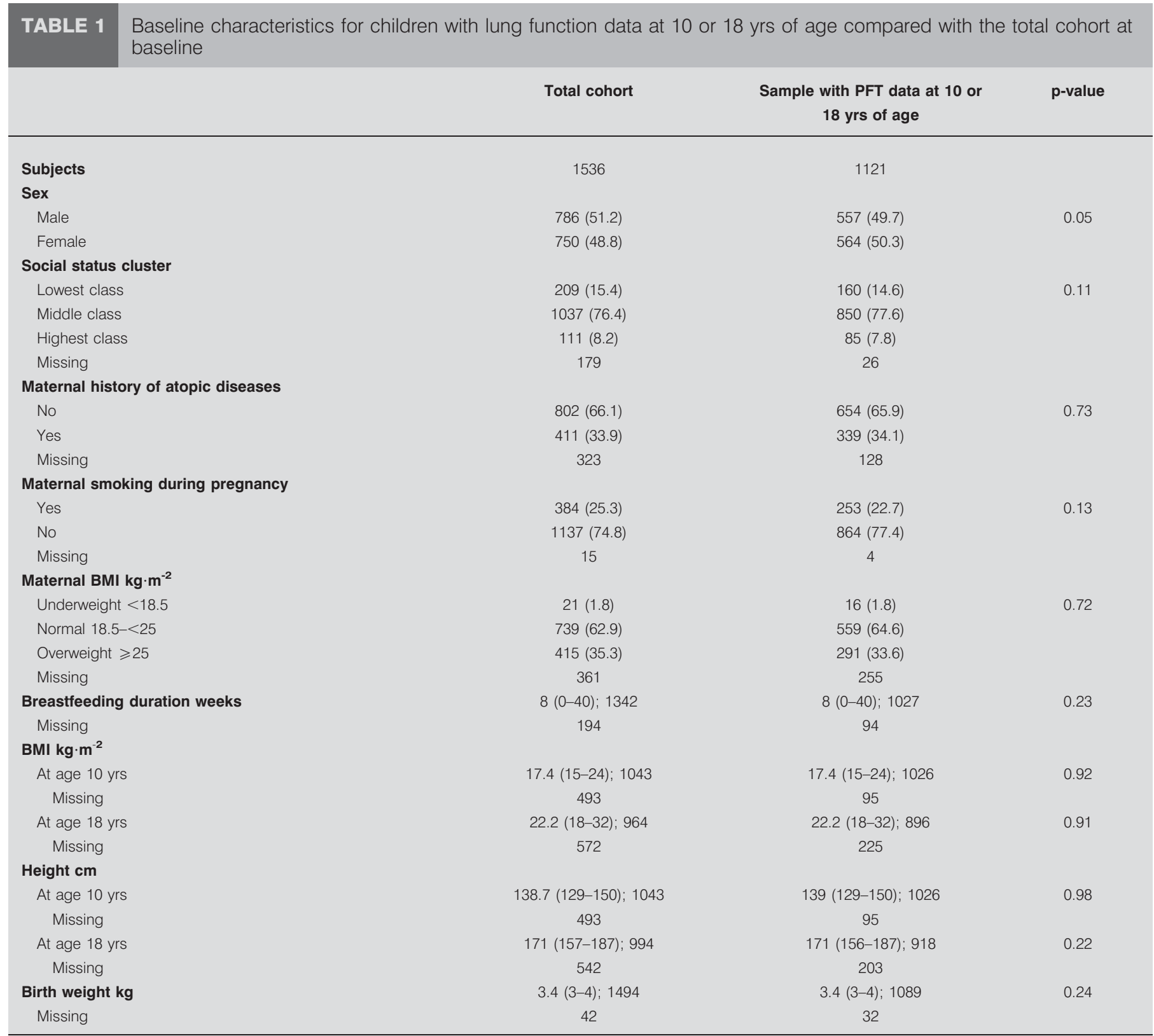

Data are presented as $n, n$ (\%) or median (5th-95th percentile) $n$, unless otherwise stated. PFT: pulmonary function test; BMI: body mass index.

Results of the path analysis, including birth weight, breastfeeding duration, sex, first-year weight gain, height, weight and FVC at 10 and $18 \mathrm{yrs}$ of age are presented in figure 1 . The path coefficients suggested a direct effect of breastfeeding on FVC at 10 yrs of age in which longer breastfeeding duration increased FVC, but no direct effect on FVC at 18 yrs of age (fig. 1). However, as FVC at 10 yrs of age explains FVC at 18 yrs of age, the effect of breastfeeding duration was detected at 10 yrs of age and then carried forward (indirect effect) to FVC at 18 yrs of age with FVC at $10 \mathrm{yrs}$ of age acting as an intervening variable (fig. E1 online supplement). We did not find any association for first-year weight gain and FVC at 18 yrs of age. For every kilogram of weight gain in the first year there was a direct increase in FVC at 10 yrs of age (path coefficient 0.064 ), but not at 18 yrs of age (fig. 1). In addition, infant weight gain had a positive indirect effect on FVC at 10 yrs of age versus weight and height at 10 yrs of age (fig. E1 online supplement).

Breastfeeding was inversely associated with first-year weight gain (path coefficient -0.089) (fig. 1). It seems that infants who were breastfed for longer gained less weight than those who were not breastfed or had a shorter duration of breastfeeding.

Regarding birth weight, this had an inverse association with first-year weight gain (path coefficient -0.079) (fig. 1). Birth weight had a direct effect on FVC at 10 yrs of age but not at 18 yrs of age (fig. 1).

As expected, height increased lung volume at 10 yrs of age. For every centimetre increase in height at $10 \mathrm{yrs}$ of age there was an increase in FVC (path coefficient 0.613) (fig. 1). Thus, taller 


\begin{tabular}{|c|c|c|c|c|c|}
\hline \multirow[t]{3}{*}{ TABLE 2} & $\begin{array}{l}\text { bre } \\
18\end{array}$ & fedin & $\begin{array}{l}7 \text { forc } \\
\text { heic }\end{array}$ & vital & pacity \\
\hline & \multicolumn{4}{|c|}{ Height $\mathrm{cm}$} & \multirow[t]{2}{*}{ p-value ${ }^{+}$} \\
\hline & 160 & 170 & 180 & 190 & \\
\hline \multicolumn{6}{|l|}{$\begin{array}{l}\text { Breastfeeding } \\
\text { months }\end{array}$} \\
\hline Not breastfeeding & 4.62 & 5.29 & 5.95 & 6.47 & \\
\hline$<2$ & 4.71 & 5.30 & 5.88 & 6.51 & 0.25 \\
\hline $2-3$ & 4.75 & 5.34 & 5.93 & 6.46 & 0.32 \\
\hline$\geqslant 4$ & 4.85 & 5.38 & 5.92 & 6.62 & 0.04 \\
\hline \multicolumn{6}{|c|}{$\begin{array}{l}\text { Data are presented as litres, unless otherwise stated. }{ }^{\#}: \mathrm{n}=586 ;{ }^{\bullet}: \text { adjusted for } \\
\text { height }(\mathrm{cm}) \text {, sex, maternal smoking during pregnancy, birth weight }(\mathrm{kg}) \text { and } \\
\text { maternal body mass index }\left(\mathrm{kg} \cdot \mathrm{m}^{-2}\right) ;{ }^{+}: \text {the interaction between breastfeeding } \\
\text { and height. }\end{array}$} \\
\hline
\end{tabular}

children had a larger lung capacity at $10 \mathrm{yrs}$ of age. Furthermore, height increased FVC at 18 yrs of age (path coefficient 0.603) (fig. 1).

Regarding sex, females tended to gain less weight in the first year of life (path coefficient -0.316) compared with males (fig. 1). In addition, they had lower FVC in early and late adolescence (path coefficient -0.154 and -0.134 , respectively) than males (fig. 1).

\section{DISCUSSION}

The main finding of this study was that the effect of a longer duration of breastfeeding on lung capacity detected at $10 \mathrm{yrs}$ of age was retained at 18 yrs of age. In addition, a longer duration of breastfeeding was related to higher FEV1. However, after adjustment of FEV1 for lung volume (FVC), breastfeeding was no longer associated with FEV1. This suggests that while breastfeeding increased the child's lung volumes, it had no influence on airway obstruction as FEV1/FVC ratios remained unchanged. The results from path analyses suggested that breastfeeding duration had a direct effect on FVC at 10 yrs of age but not at $18 \mathrm{yrs}$ of age. Nevertheless, the effect of breastfeeding duration at 10 yrs of age was carried forward to 18 yrs of age. Although weight gain in infancy takes away some of the direct effect of breastfeeding on FVC at 10 yrs of age (statistically significant negative association with breastfeeding duration and positive association with FVC), breastfeeding continues to support its beneficial effect on lung volume through late adolescence. The results from the path analyses were in agreement with the repeated measurement models, showing a continuing protective effect of breastfeeding on FVC up to 18 yrs of age.

We compared the total cohort with our analytic sample for potential selection biases but found no evidence for a selection (table 1). The probability that our results were influenced by a selection bias was minimal since $73 \%(1,121$ out of 1,536$)$ of the birth cohort participated in the PFTs either at 10 or 18 yrs of age. PFT data were assessed under standard conditions in the clinic at the 10- and 18-yr visits, reducing information biases. Furthermore, breastfeeding information was ascertained prospectively at 1 and 2 yrs of age, which minimised recall bias; however, we did not assess whether breastfeeding was directly at the breast, indirect via bottle use or exclusive (only breast milk).

Birth length and length gain in the first year were not collected, which is a limitation of our study. Some studies have used birth weight and weight gain $[15,16]$, others have focused on length and length gain in infancy [25]. The specific role of both markers has not been determined. We found that birth weight is statistically significantly associated with height at 10 and 18 yrs of age ( $\mathrm{r}_{\mathrm{s}} 0.19$ and 0.28 , respectively) and so is infancy weight gain ( $\mathrm{r}_{\mathrm{s}} 0.33$ and 0.35 , respectively). The positive correlation of birth weight and infancy weight gain with height may only be a substitute for the correlation between early length

TABLE 3 Adjusted estimated effects of repeated measurement of lung function at 10 and 18 yrs of age using linear mixed regression model ${ }^{\#}$

\begin{tabular}{|c|c|c|c|c|c|c|}
\hline & \multicolumn{2}{|c|}{ FVC } & \multicolumn{2}{|c|}{ FEV 1} & \multicolumn{2}{|c|}{ FEV $1 /$ FVC } \\
\hline & Estimate $\pm \mathrm{SE} \mathrm{mL}$ & p-value & Estimate $\pm \mathrm{SE} \mathrm{mL}$ & p-value & Estimate $\pm \mathrm{SE} \%$ & p-value \\
\hline Breastfeeding duration weeks & $1.48 \pm 0.60$ & 0.01 & $1.21 \pm 0.58$ & 0.03 & $-0.001 \pm 0.01$ & 0.92 \\
\hline Females & $-103.7 \pm 18.09$ & $<0.0001$ & $-40.16 \pm 17.50$ & 0.02 & $1.93 \pm 0.42$ & $<0.0001$ \\
\hline BMI $\mathbf{k g} \cdot \mathrm{m}^{-2}$ & $6.63 \pm 3.04$ & 0.02 & $-0.65 \pm 2.87$ & 0.82 & $-0.24 \pm 0.05$ & $<0.0001$ \\
\hline Height cm & $46.13 \pm 1.29$ & $<0.0001$ & $39.81 \pm 1.21$ & $<0.0001$ & $-0.05 \pm 0.02$ & 0.01 \\
\hline Maternal atopic diseases & $29.87 \pm 18.72$ & 0.11 & $19.57 \pm 18.03$ & 0.27 & $0.01 \pm 0.43$ & 0.96 \\
\hline Age yrs & $103.1 \pm 5.75$ & $<0.0001$ & $91.93 \pm 5.31$ & $<0.0001$ & $0.23 \pm 0.10$ & 0.02 \\
\hline Birth weight kg & $23.45 \pm 17.49$ & 0.18 & $41.16 \pm 16.83$ & 0.01 & $0.57 \pm 0.40$ & 0.15 \\
\hline \multicolumn{7}{|l|}{ Maternal BMI $\mathbf{k g} \cdot \mathrm{m}^{-2}$} \\
\hline Underweight $<18.5$ & $36.99 \pm 69.87$ & 0.59 & $24.05 \pm 67.37$ & 0.72 & $-1.21 \pm 1.64$ & 0.45 \\
\hline Overweight $\geqslant 25$ & $53.24 \pm 19.46$ & 0.006 & $-47.56 \pm 18.72$ & 0.01 & $-0.01 \pm 0.45$ & 0.98 \\
\hline Normal $18.5-<25$ & Ref. & & Ref. & & Ref. & \\
\hline
\end{tabular}

FVC: forced vital capacity; FEV1: forced expiratory volume in $1 \mathrm{~s}$; BMI: body mass index; Ref: reference. ${ }^{\#}: 760$ subjects and 1,205 observations. 
indicators and height at older age. However, this correlation explains that higher birth weight and infancy weight gain are related to increased lung volume via longer height.

We controlled for confounders in our analyses (table 3), but focused on a manageable set of confounders. Our main focus in this analysis was the effect of early post-natal exposures on lung function in childhood and late adolescence. We considered some additional potentially distorting effects, such as the fact that respiratory infection and maternal smoking may reduce lung capacity in children [26]; however, we found no association (data not shown). Our analytical path model will allow us to integrate additional influences involved in childhood and adolescence in future analyses.

\section{Relationship between breastfeeding duration and lung function at 10 and 18 yrs of age}

The repeated measurement analysis demonstrates that for every week increase in duration of breastfeeding, the FVC at 10 and 18 yrs of age was increased on average by $1.48 \mathrm{~mL}(95 \% \mathrm{CI}$ 0.29-2.67 L). This is comparable to the study by OGBUANU et al. [14] which reported an average of $1.6 \mathrm{~mL}$ per week of breastfeeding at $10 \mathrm{yrs}$ of age (re-analysis using a continuous breastfeeding variable). For instance, the median duration of breastfeeding ( 8 weeks) was related to an increase in FVC of $11.84 \mathrm{~mL}$. Similarly, the Tucson Children Respiratory Survey showed that a longer duration of breastfeeding was associated with increased FVC in the total cohort at 11 and 16 yrs of age; however, only in the absence of maternal asthma [13]. A Swedish population-based cohort study found that children exclusively breastfed for $\geqslant 4$ months had significantly higher peak expiratory flows at 4 and 8 yrs of age $[5,6]$.

In our analysis, we found that height at 18 yrs of age modified the effect of breastfeeding on FVC at the same age. We demonstrated that the decline was related to an interaction between height at $18 \mathrm{yrs}$ of age and breastfeeding, showing that the effect of breastfeeding on FVC at 18 yrs of age disappears when children grow. Lung volume experiences an increase until pulmonary maturation at 20-25 yrs of age [27, 28]. Our results suggest that breastfeeding contributes to lung growth in childhood and adolescence; however, somatic growth in adolescence may capture most of the effects on the increases in lung volume. Hence, it is possible that the effect of breastfeeding on lung volume dissipates in young adults. An alternative explanation is that height is a powerful driver of lung volume that, when evaluating the effect of breastfeeding, can only be detected in shorter children.

\section{Relationship between breastfeeding duration, first-year weight gain and lung function at 10 and 18 yrs of age: path analysis}

Although breastfeeding does not seem to directly influence lung capacity at 18 yrs of age, it does directly improve the lung volume at 10 yrs of age, which in turn is related to higher FVC at $18 \mathrm{yrs}$ of age. Therefore, better lung function at $10 \mathrm{yrs}$ of age contributes to an increased FVC in late adolescence.

As expected, we observed that breastfeeding duration was inversely associated with the child's weight gain in the first year. This is similar to the results reported by TURNER et al. [15], demonstrating that exclusive breastfeeding compared with formula feeding was associated with a mean reduction in weight gain at 12 months of age. Our findings are in agreement with a study by HANCOx et al. [29] reporting higher functional residual capacity related to higher weight gain from birth to 3 yrs of age, but may differ from the findings of two studies that reported early-infancy weight gain was associated with reduced lung growth (measured at 1 and 12 months and 514 weeks of age) $[15,16]$. It is possible that weight gain in infancy negatively affects early lung growth. In contrast to the infant weight gain studies, we measured FVC at 10 and 18 yrs of age and found a positive impact of weight gain. The positive effect of weight gain is further supported by the finding that weight gain in infancy is correlated with increased height in adolescence, which in turn is associated with lung volume (as discussed previously). Similarly, TURNER et al. [15] found that weight gain in infancy is related to increased mid-expiratory flow at 11 yrs of age; however, their explanatory model did not include breastfeeding. To decipher the role of infant weight gain from that of breastfeeding on lung volume at 10 and 18 yrs of age, we could not use breastfeeding and weight gain as confounders in the same model since weight gain is considered to be on the "causal pathway" between breastfeeding and lung volume. Path analyses offered a unique opportunity to explore these relationships.

The mechanism of how breastfeeding influences lung function is unknown. As described in the literature, sucking is related to innervations of the diaphragm [30] and abdominal breathing exercises contribute to lung capacity. Evidence suggests that for $75 \mathrm{~s}$ prior to milk ejection, there is an approximated negative pressure of $98 \mathrm{mmHg}$ among breastfed infants, which is three times stronger than bottle-fed infants [31]. Breastfed infants have an average of $8 \mathrm{~min}$ of sucking, which is nearly twice as long as the bottle feeding (average $4.4 \mathrm{~min}$ ). Bottle feeding is also related to a higher rate of swallowing with more frequent interruption of breathing $[32,33]$. In addition, recent research demonstrates that the olfactory response of the infant to areolar gland secretions increases the abdominal inspiration of the infant [34]. Thus, direct breastfeeding may create an increased diaphragmatic force stimulating increased lung growth. However, no study has investigated this hypothesis. Future research is needed to investigate mechanisms on how suckling may enhance lung volume and development.

In conclusion, we suggest that breastfeeding improves lung function and this effect is partially diminished by weight gain in infancy. The use of path models improved the understanding of "causal pathways" in longitudinal studies, allowing estimation of the direct, indirect and total effects of different covariates. Future studies should aim to better understand the potential mechanistic implications of breastfeeding on lung development.

\section{SUPPORT STATEMENT}

This study was funded, in part by, the National Institutes of Health (NIH) R01 AI061471 (principle investigator S.H. Arshad). The 10-yr follow-up of this study was funded by National Asthma Campaign, UK (grant no. 364) and the 18-yr follow-up by NIH R01 AI061471.

\section{STATEMENT OF INTEREST}

None declared. 


\section{ACKNOWLEDGEMENTS}

The authors gratefully acknowledge the cooperation of the children and parents who participated in this study, and appreciate the hard work of S. Matthews (David Hyde Asthma Research Center, Isle of Wight, UK) and the Isle of Wight research team in collecting data. We would like to acknowledge the helpful comments of K. Clark (University of South Carolina, Columbia, SC, USA) for the revision of the manuscript.

\section{REFERENCES}

1 Howie PW, Forsyth JS, Ogston SA, et al. Protective effect of breast feeding against infection. BMJ 1990; 300: 11-16.

2 Gdalevich M, Mimouni D, Mimouni M. Breast-feeding and the risk of bronchial asthma in childhood: a systematic review with meta-analysis of prospective studies. J Pediatr 2001; 139: 261-266.

3 Bener A, Ehlayel MS, Alsowaidi S, et al. Role of breast feeding in primary prevention of asthma and allergic diseases in a traditional society. Eur Ann Allergy Clin Immunol 2007; 39: 337-343.

4 Oddy WH, Holt PG, Sly PD, et al. Association between breast feeding and asthma in 6 year old children: findings of a prospective birth cohort study. BMJ 1999; 319: 815-819.

5 Kull I, Melen E, Alm J, et al. Breast-feeding in relation to asthma, lung function, and sensitization in young school children. J Allergy Clin Immunol 2010; 125: 1013-1019.

6 Kull I, Almqvist C, Lilja G, et al. Breast-feeding reduces the risk of asthma during the first 4 years of life. J Allergy Clin Immunol 2004; 114: 755-760.

7 Giwercman C, Halkjaer LB, Jensen SM, et al. Increased risk of eczema but reduced risk of early wheezy disorder from exclusive breast-feeding in high-risk infants. J Allergy Clin Immunol 2010; 125: 866-871.

8 Wright AL, Holberg CJ, Taussig LM, et al. Factors influencing the relation of infant feeding to asthma and recurrent wheeze in childhood. Thorax 2001; 56: 192-197.

9 Sears MR, Greene JM, Willan AR, et al. Long-term relation between breastfeeding and development of atopy and asthma in children and young adults: a longitudinal study. Lancet 2002; 360: 901-907.

10 Burgess SW, Dakin CJ, O'Callaghan MJ. Breastfeeding does not increase the risk of asthma at 14 years. Paediatrics 2006; 117: e787-e792.

11 Kramer MS, Matush L, Vanilovich I, et al. Effect of prolonged and exclusive breast feeding on risk of allergy and asthma: cluster randomised trial. BMJ 2007; 335: 815.

12 Rust GS, Thompson CJ, Minor P, et al. Does breastfeeding protect children from asthma? Analysis of NHANES III survey data. J Natl Med Assoc 2001; 93: 139-148.

13 Guilbert TW, Stern DA, Morgan WJ, et al. Effect of breastfeeding on lung function in childhood and modulation by maternal asthma and atopy. Am J Respir Crit Care Med 2007; 176: 843-848.

14 Ogbuanu IU, Karmaus W, Arshad SH, et al. Effect of breastfeeding duration on lung function at age 10 years: a prospective birth cohort study. Thorax 2009; 64: 62-66.

15 Turner S, Zhang G, Young S, et al. Associations between postnatal weight gain, change in postnatal pulmonary function, formula feeding and early asthma. Thorax 2008; 63: 234-239.
16 Lucas JS, Inskip HM, Godfrey KM, et al. Small size at birth and greater postnatal weight gain: relationships to diminished infant lung function. Am J Respir Crit Care Med 2004; 170: 534-540.

17 Kurukulaaratchy RJ, Fenn MH, Waterhouse LM, et al. Characterization of wheezing phenotypes in the first 10 years of life. Clin Exp Allergy 2003; 33: 573-578.

18 Arshad SH, Hide DW. Effect of environmental factors on the development of allergic disorders in infancy. J Allergy Clin Immunol 1992; 90: 235-241.

19 Scott M, Raza A, Karmaus W, et al. Influence of atopy and asthma on exhaled nitric oxide in an unselected birth cohort study. Thorax 2010; 65: 258-262.

20 Standardization of Spirometry, 1994 Update. American Thoracic Society. Am J Respir Crit Care Med 1995; 152: 1107-1136.

21 The Office for National Statistics. The National Statistics Socioeconomic Classification: Origins, Development and Use. Basingstoke, Palgrave Macmillan, 2005.

22 Wolfinger R, Chang M. Comparing the SASI ${ }_{\circledast}$ GLM and MIXED Procedures for Repeated Measures. www.ats.ucla.edu/stat/sas/ library/mixedglm.pdf Date last accessed: January 1, 2010.

23 Bollen K, ed. Structural Equations with Latents Variables. New York, John Wiley \& Son, 1989.

24 Hatcher L, ed. A Step-by-Step Approach to Using SAS for Factor Analysis and Structural Equation Modeling. Cary, SAS Institute Inc., 1994

25 Stein CE, Kumaran K, Fall CH, et al. Relation of fetal growth to adult lung function in south India. Thorax 1997; 52: 895-899.

26 Karmaus W, Dobai AL, Ogbuanu I, et al. Long-term effects of breastfeeding, maternal smoking during pregnancy, and recurrent lower respiratory tract infections on asthma in children. J Asthma 2008; 45: 688-695.

27 Quanjer Ph, Stocks J, Polgar G, et al. Compilation of reference values for lung function measurements in children. Eur Respir J 1989; 2: Suppl. 4, 184s-261s.

28 Zeman KL, Bennett WD. Growth of the small airways and alveoli from childhood to the adult lung measured by aerosol-derived airway morphometry. J Appl Physiol 2006; 100: 965-971.

29 Hancox RJ, Poulton R, Greene JM, et al. Associations between birth weight, early childhood weight gain and adult lung function. Thorax 2009; 64: 228-232.

30 Miller MJ, Kiatchoosakun P. Relationship between respiratory control and feeding in the developing infant. Semin Neonatol 2004; 9: 221-227.

31 Mizuno K, Ueda A. Changes in sucking performance from nonnutritive sucking to nutritive sucking during breast- and bottle-feeding. Pediatr Res 2006; 59: 728-731.

32 Goldfield EC, Richardson MJ, Lee KG, et al. Coordination of sucking, swallowing, and breathing and oxygen saturation during early infant breast-feeding and bottle-feeding. Pediatr Res 2006; 60: $450-455$

33 Koenig JS, Davies AM, Thach BT. Coordination of breathing, sucking, and swallowing during bottle feedings in human infants. J Appl Physiol 1990; 69: 1623-1629.

34 Doucet $\mathrm{S}$, Soussignan $\mathrm{R}$, Sagot $\mathrm{P}$, et al. The secretion of areolar (Montgomery's) glands from lactating females elicits selective, unconditional responses in neonates. PLoS One 2009; 4: e7579. 